\title{
Teaching NeuroImages: Intracranial foreign body reaction after endovascular procedures
}

Enrico Giordan, MD, * Waleed Brinjikji, MD,* and Giuseppe Lanzino, MD*

Neurology ${ }^{\circledR}$ 2018;90:296-297. doi:10.1212/WNL.0000000000004938

\section{Correspondence}

Dr. Lanzino

lanzino.giuspeppe@mayo. edu

Figure 1 Left internal carotid artery (ICA) aneurysm on cerebral angiogram and rationale behind pipeline placement
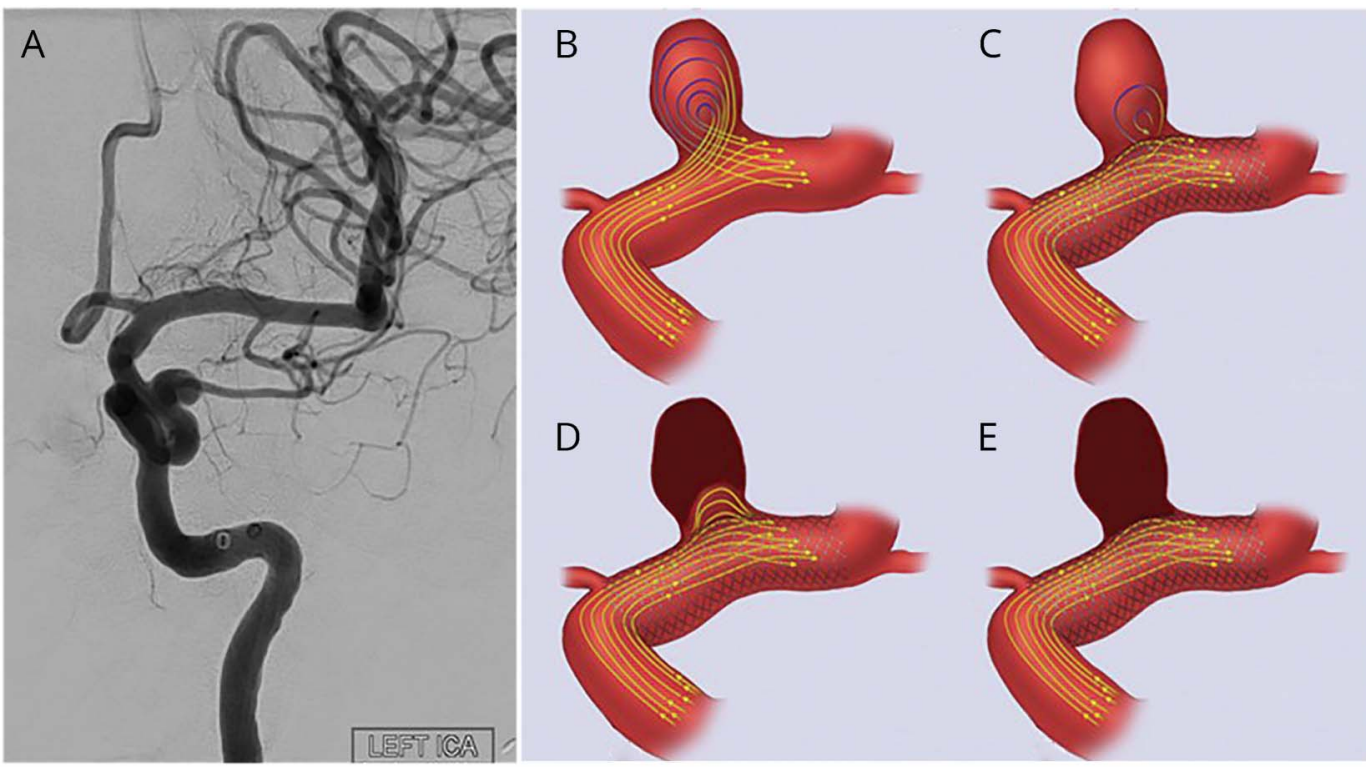

(A) Cerebral angiogram shows a 6-mm periophthalmic left ICA aneurysm. Drawing of flow diversion for intracranial aneurysms. (B) Blood flow through an untreated aneurysm. (C) Flow diverter placed in the parent vessel redirects blood causing intra-aneurysmal stasis. (D) Progressive intra-aneurysmal thrombosis leads to $(E)$ aneurysm occlusion.

A 64-year-old woman with a family history of aneurysmal subarachnoid hemorrhage was diagnosed with an incidental aneurysm during screening. The aneurysm was treated with flow diversion (figure 1). Two months later, she complained of headache and intermittent wordfinding difficulty. Brain MRI demonstrated multiple areas of nodular enhancement ipsilateral to the treated aneurysm (figure 2A). After a 6-week course of oral steroids, both the radiologic findings and her symptoms resolved (figure 2, C and D). This patient's clinical course and imaging findings are consistent with a foreign body reaction occasionally seen after endovascular treatment. This is related to an allergic reaction to microparticles sheared from catheters/ devices during endovascular procedures. ${ }^{1,2}$

\section{Author contributions}

Enrico Giordan: manuscript preparation, drafting manuscript, collection of data and figures, approval of final version. Waleed Brinjikji: manuscript preparation, drafting manuscript,

\section{MORE ONLINE}

\section{$\rightarrow$ Teaching Slides:}

links.lww.com/WNL/A205

*These authors contributed equally to this work.

From the Departments of Neurosurgery (E.G., W.B., G.L.) and Radiology (W.B., G.L.), Mayo Clinic, Rochester, MN.

Go to Neurology.org/N for full disclosures. Funding information and disclosures deemed relevant by the authors, if any, are provided at the end of the article. 
Figure 2 Brain MRI shows presentation, progression, and resolution of foreign body reaction
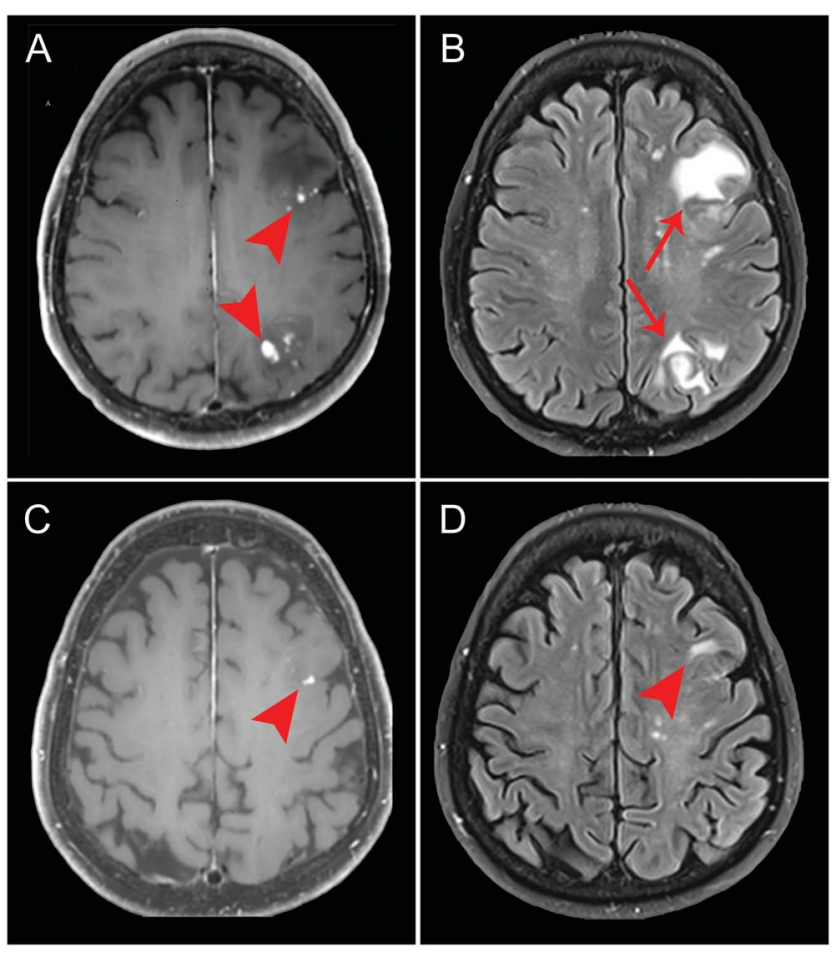

(A) T1-contrast-enhanced MRI 2 months after treatment shows nodular enhancement in the left frontal and parietal lobes (arrowheads). (B) T2enhanced/fluid-attenuated inversion recovery MRI shows marked edema/ T2 changes in the region of nodular enhancement (arrow). (C) Four months later, MRI shows marked reduction in enhancement and (D) improvement in edema/T2 changes (arrowheads). collection of data and figures, approval of final version. Giuseppe Lanzino: manuscript preparation, drafting manuscript, collection of data and figures, approval of final version.

\section{Study funding}

No targeted funding reported.

\section{Disclosure}

The authors report no disclosures relevant to the manuscript. Go to Neurology.org/N for full disclosures.

\section{References}

1. Cruz JP, Marotta T, O’Kelly C, et al. Enhancing brain lesions after endovascular treatment of aneurysms. AJNR Am J Neuroradiol 2014;35:1954-1958.

2. Lorentzen AO, Nome T, Bakke SJ, Scheie D, Stenset V, Aamodt AH. Cerebral foreign body reaction after carotid aneurysm stenting. Interv Neuroradiol 2016;22: $53-57$.

\section{Disputes \& Debates: Rapid online correspondence}

The editors encourage comments on recent articles through Disputes \& Debates:

Access an article at Neurology.org/N and click on "COMMENT" beneath the article header. Responses will be posted within 3 business days.

Before submitting a comment to Disputes \& Debates, remember the following:

- Disputes \& Debates is restricted to comments about studies published in Neurology within the last eight weeks

- Read previously posted comments; redundant comments will not be posted

- Your submission must be 200 words or less and have a maximum of five references; reference one must be the article on which you are commenting

- You can include a maximum of five authors (including yourself) 


\section{Neurology}

\section{Teaching NeuroImages: Intracranial foreign body reaction after endovascular procedures}

Enrico Giordan, Waleed Brinjikji and Giuseppe Lanzino

Neurology 2018;90;296-297

DOI 10.1212/WNL.0000000000004938

\section{This information is current as of February 5, 2018}

Updated Information \& Services

References

Permissions \& Licensing

Reprints including high resolution figures, can be found at: http://n.neurology.org/content/90/6/296.full

This article cites 2 articles, 1 of which you can access for free at: http://n.neurology.org/content/90/6/296.full\#ref-list-1

Information about reproducing this article in parts (figures,tables) or in its entirety can be found online at:

http://www.neurology.org/about/about_the_journal\#permissions

Information about ordering reprints can be found online:

http://n.neurology.org/subscribers/advertise

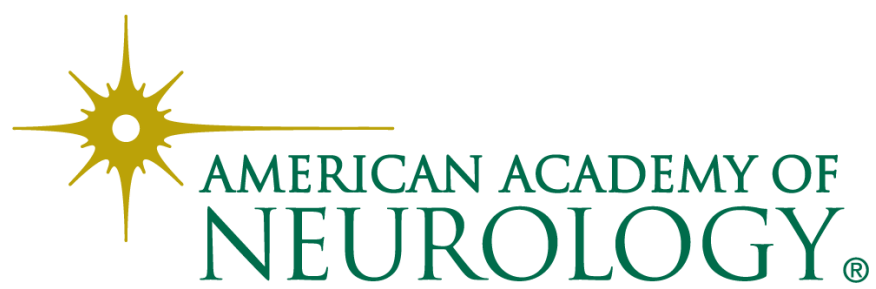

